\title{
Non-Descemet's stripping automated endothelial keratoplasty for bullous keratopathy secondary to iridoschisis
}

This article was published in the following Dove Press journal:

Clinical Ophthalmology

2 July 2013

Number of times this article has been viewed

\author{
Teruumi Minezaki \\ Takaaki Hattori \\ Hayate Nakagawa \\ Shigeto Kumakura \\ Hiroshi Goto \\ Department of Ophthalmology, \\ Tokyo Medical University, \\ Shinjukuku, Tokyo, Japan
}

Correspondence: Shigeto Kumakura Department of Ophthalmology,

Tokyo Medical University,

6-7-I Nishishinjuku, Shinjukuku,

Tokyo 160-0023, Japan

Tel +8I33342 6 I I I

$\mathrm{Fax}+81333469170$

Email s-kuma@tokyo-med.ac.jp
Purpose: To report a case of bullous keratopathy secondary to iridoschisis treated by nonDescemet's stripping automated endothelial keratoplasty (nDSAEK).

Case report: A 79-year-old woman was referred to our hospital with loss of vision in the left eye. Slit lamp examination of her left eye showed a shallow anterior chamber with cataract and schisis in the inferior quadrant of iris stroma. Bullous keratopathy secondary to iridoschisis was diagnosed. Cataract surgery with iridectomy succeeded to deepen the anterior chamber and remove the floating iris leaf, although corneal edema remained. Four days later, nDSAEK was performed, which resolved corneal edema and restored visual acuity.

Conclusion: The two-step surgery of cataract surgery plus iridectomy followed by nDSAEK may be an effective strategy for treating bullous keratopathy secondary to iridoschisis.

Keywords: iridoschisis, bullous keratopathy, non-Descemet's stripping automated endothelial keratoplasty

\section{Introduction}

Iridoschisis is a rare condition characterized by separation of the anterior iris from the posterior iris stroma. ${ }^{1}$ Glaucoma is a common ocular disorder secondary to iridoschisis. ${ }^{2-5}$ On the other hand, corneal disorder secondary to iridoschisis is rare, ${ }^{6}$ and only a few cases of secondary bullous keratopathy have been reported..$^{7-10}$ Penetrating keratoplasty was the conventional treatment for bullous keratopathy secondary to iridoschisis. We report here a case of bullous keratopathy caused by iridoschisis, and non-Descemet's stripping automated endothelial keratoplasty (nDSAEK) conducted after cataract surgery with sectoral iridectomy succeeded to restore corneal transparency and visual acuity. To the best of our knowledge, this is the first report of nDSAEK treatment for bullous keratopathy secondary to iridoschisis.

\section{Case report}

A 79-year-old woman was referred to our hospital for further investigations and treatment of bullous keratopathy in her left eye. At presentation to Tokyo Medical University Hospital, her best corrected visual acuity (BCVA) was hand movements in the right eye and 0.7 in the left eye. Intraocular pressure was $8 \mathrm{mmHg}$ in the left eye and not determined in the right eye. Slit lamp examination of the right eye showed bullous keratopathy and virtually nonexistent anterior chamber. According to her past history, bullous keratopathy in her right eye had progressed after extracapsular cataract extraction with implantation of an intraocular lens for the treatment of glaucoma attack. Slit lamp examination of her left eye showed a shallow anterior chamber, with 
cataract and schisis of the iris stroma in the inferior quadrant. A localized area of diffuse corneal edema was observed, at the site where the separated anterior iris leaf touched the corneal endothelium (Figure 1A and B). Anterior segment optical coherence tomography (AS-OCT, Casia, Tomey Corporation, Nagoya, Japan) confirmed that the anterior leaf was separated and touched the corneal endothelium (Figure 1C). The remaining portion of the iris appeared normal. The superior cornea could be evaluated by specular microscopy (Nonconrobo II, FA3809, Konan Medical, Inc., Hyogo, Japan) but not the central and inferior cornea because of corneal edema. The endothelial cell density at superior cornea was 354 cells $/ \mathrm{mm}^{2}$ (Figure 1D).

These examinations clearly suggested that corneal edema in the left eye was related to decompensation of the corneal endothelium caused by contact with the separated anterior iris leaf. Therefore, we first planned cataract surgery with iridectomy to remove the separated anterior iris leaf in order to release the iridocorneal contact. The poorly dilated pupil was stretched by sphincterotomy (Yae scissors, M.E. Technica, Tokyo, Japan) and iris-retractor hooks (Alcon Grieshaber, Schaffhauser, Switzerland). Subsequently, phacoemulsification and aspiration were performed via a superior sclerocorneal tunnel with viscoelastic protection of the corneal endothelium. After implantation of an acrylic foldable intraocular lens (Alcon Laboratories, Inc., Fort Worth, TX, USA) in the capsular bag, the separated anterior iris leaf was removed with a $23 \mathrm{G}$ vitreocutter (Alcon Laboratories). A slit lamp photograph after surgery showed that the separated anterior
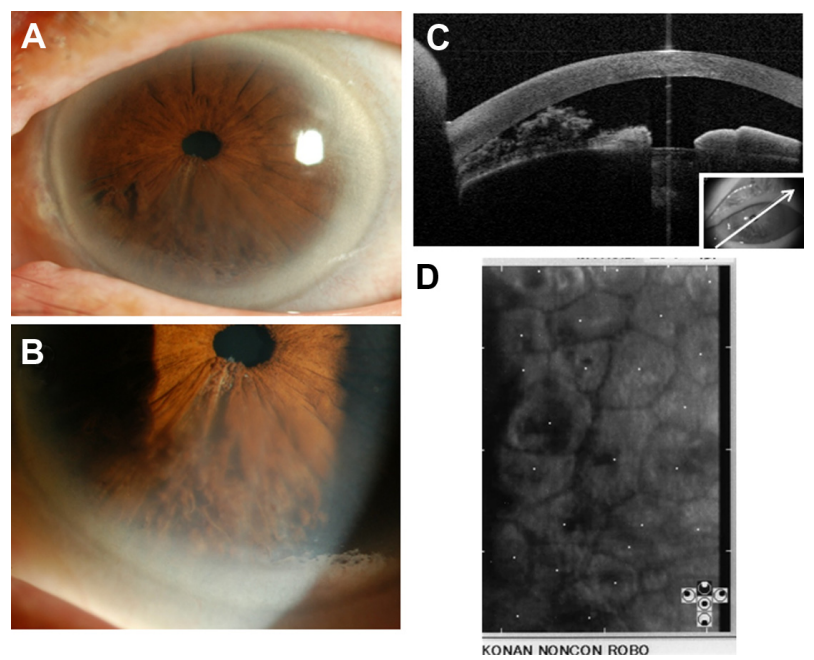

KONAN NONCON ROBO

Figure I Slit lamp photographs, anterior segment optical coherence tomography (AS-OCT) image, and specular micrograph of the left eye before surgery. Slit lamp microscopy reveals iridoschisis in the inferior quadrant (A) and partial corneal edema in this portion (B). AS-OCT depicts a shallow anterior chamber with a separated anterior leaf of the iris touching the corneal endothelium (C). Specular microscopy of superior cornea shows endothelial cell loss (D).
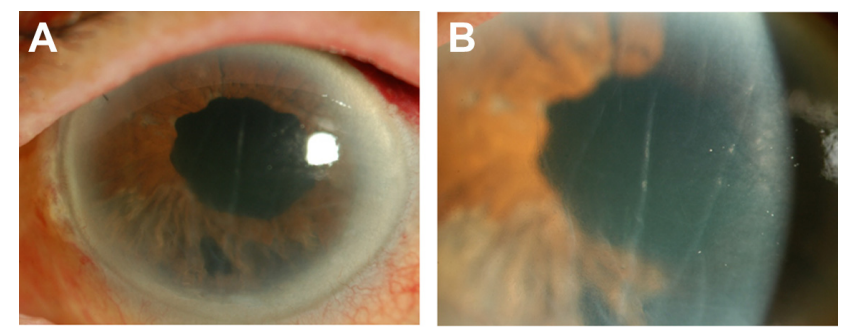

Figure 2 Slit lamp photographs of the left eye after cataract surgery with iridectomy. After the first surgery, slit lamp microscopy shows the implanted intraocular lens and partial removal of the iris in the lower quadrant $(\mathbf{A})$. Corneal edema with Descemet's folds are observed even in central corneal stroma (B).

Note: The pupil appears slightly dilated due to the sphincterotomy and use of iris-retractor hooks during operation.

iris leaf had been removed by iridectomy (Figure 2A), but the area of corneal edema was enlarged (Figure 2B).

On day 4 after the first surgery, we performed nDSAEK ${ }^{11}$ with double-glide donor insertion technique ${ }^{12}$ to restore corneal transparency. An $8 \mathrm{~mm}$ diameter donor endothelial lamella was pulled through a $5.5 \mathrm{~mm}$ temporal sclerocorneal incision into the anterior chamber without removing the recipient's endothelium. After surgery, the transplanted cornea adhered to the recipient cornea and corneal edema was resolved. A slit lamp photograph taken at 6 months after operation showed that the recipient and grafted cornea were transparent (Figure 3A). AS-OCT revealed good adherence of the graft to the recipient cornea (Figure $3 \mathrm{~B}$ ). The BCVA of her left eye improved to 1.0 and endothelial cell density of central cornea was 2174 cells $/ \mathrm{mm}^{2}$ at 18 months after transplantation (Figure 3C). The cornea has remained clear without occurrence of graft rejection. We also did not observe any recurrence of iridoschisis during 18 months after operation.
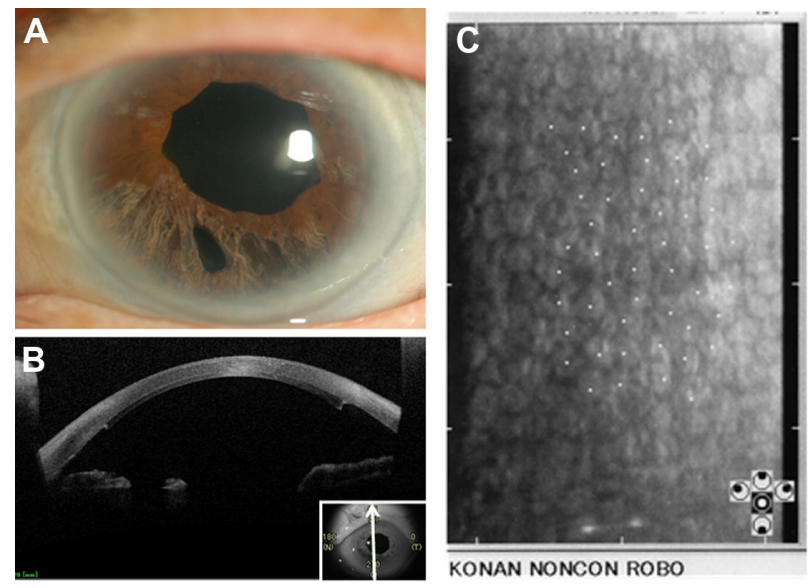

Figure 3 Slit lamp photograph, anterior segment optical coherence tomography (AS-OCT) image, and specular micrograph of the left eye after surgery. Slit lamp photograph at 6 months after nDSAEK shows that corneal edema has resolved (A). The pupil is slightly dilated with irregular margin due to sphincterotomy, and inferior iris atrophy is due to iridectomy. Other part of the iris is normal. AS-OCT image at 6 months post-nDSAEK shows adherence of the transplanted graft to recipient's cornea, and iris defect due to iridectomy (B). Specular micrograph at 18 months post-nDSAEK shows high endothelial cell density in the center of the cornea $(\mathbf{C})$. 


\section{Discussion}

In this case, since the degenerate iris strands in contact with the corneal endothelium caused corneal edema, removal of the detached iris strands was essential to prevent total corneal endothelial decompensation. However, because of the shallow anterior chamber, cutting the separated anterior leaf from the iris without losing corneal endothelial cells would be difficult. Moreover, if corneal endothelial cell loss deteriorates to total decompensation, surgical stress could deteriorate bullous keratopathy. Hence, we proposed a two-step treatment strategy. In the first surgery, cataract was removed to deepen the anterior chamber before the iris strands were removed safely. In the second surgery, nDSAEK was performed for bullous keratopathy.

The two-step surgery has some advantages. First, corneal edema may decrease or disappear by cataract surgery with iridectomy alone. ${ }^{10}$ In such case, DSAEK or nDSAEK is not necessary. Second, sufficient removal of the floating iris leaf by the first surgery can be confirmed before DSAEK/ nDSAEK. This is important because the endothelium of the corneal graft will be closer to the iris than the native endothelium after DSAEK/nDSAEK and iridocorneal touch must be avoided. However, there are also disadvantages. The two-step surgery requires two sclerocorneal/corneal tunnel incisions at different regions. Obviously, the two-step surgery would impose greater burden on the patient than onestep surgery. Penetrating keratoplasty was the conventional treatment for bullous keratopathy secondary to iridoschisis. ${ }^{6}$ In recent years, DSAEK and nDSAEK have been employed as the first-line treatment for bullous keratopathy because of the potential to achieve better quality vision than penetrating keratoplasty. In our case, nDSAEK achieved excellent visual outcome. To obtain good outcome, it is essential to perform DSAEK/nDSAEK at the earliest possible time from onset of corneal edema. In our patient, we performed nDSAEK relatively soon (4 days) after the first surgery because her right eye was blind. However, it is difficult to discuss the timing of surgeries because in some cases, corneal endothelial decompensation may resolve after weeks or months following cataract surgery with iridectomy.

Clinical Ophthalmology

\section{Publish your work in this journal}

Clinical Ophthalmology is an international, peer-reviewed journal covering all subspecialties within ophthalmology. Key topics include: Optometry; Visual science; Pharmacology and drug therapy in eye diseases; Basic Sciences; Primary and Secondary eye care; Patient Safety and Quality of Care Improvements. This journal is indexed on

\section{Conclusion}

In summary, we report a case of bullous keratopathy secondary to iridoschisis. Cataract surgery and iridectomy followed by nDSAEK succeeded to resolve corneal edema and restore visual acuity. This two-step surgery is an effective strategy for the treatment of bullous keratopathy secondary to iridoschisis.

\section{Disclosure}

The authors report no other conflicts of interest in this work.

\section{References}

1. Schoneveld PG, Pesudovs K. Iridoschisis. Clin Exp Optom. 1999;82: 29-33.

2. Rodrigues MC, Spaeth GL, Krachmer JH, Laibson PR. Iridoschisis associated with glaucoma and bullous keratopathy. Am J Ophthalmol. 1983;95:73-81.

3. Mills PV. Iridoschisis. Br J Ophthalmol. 1967;51:158-164.

4. Romano A, Treister G, Barishak R, Stein R. Iridoschisis and angleclosure glaucoma. Ophthalmologica. 1972;164:199-207.

5. McCulloch C. Iridoschisis as a cause of glaucoma. Am J Ophthalmol. 1950;33:1398-1400.

6. Gogaki E, Tsolaki F, Tiganita S, Skatharoudi C, Balatsoukas D. Iridoschisis: case report and review of the literature. Clin Ophthalmol. 2011;5:381-384.

7. Wang HB, Hu YX, Feng X. Corneal endothelial decompensation secondary to iridoschisis in degenerative myopic eyes: a case report. Int J Ophthalmol. 2012;5:116-118.

8. Srinivasan S, Batterbury M, Hiscott P. Bullous keratopathy and corneal decompensation secondary to iridoschisis: a clinicopathological report. Cornea. 2005;24:867-869.

9. Crosby NJ, McDonnell P, Shah P. Iridoschisis associated with nanophthalmos and bullous keratopathy. Int Ophthalmol. 2013;33: 83-85.

10. Ghanem VC, Ghanem EA, Ghanem RC. Iridectomy of the anterior iris stroma using the vitreocutter during phacoemulsification in patients with iridoschisis. J Cataract Refract Surg. 2003;29:2057-2059.

11. Kobayashi A, Yokogawa H, Sugiyama K. Non-Descemet stripping automated endothelial keratoplasty for endothelial dysfunction secondary to argon laser iridotomy. Am J Ophthalmol. 2008;146:543-549.

12. Kobayashi A, Yokogawa H, Sugiyama K. Descemet stripping with automated endothelial keratoplasty for bullous keratopathies secondary to argon laser iridotomy - preliminary results and usefulness of double-glide donor insertion technique. Cornea. 2008;27 Suppl 1: S62-S69.

\section{Dovepress}

PubMed Central and CAS, and is the official journal of The Society of Clinical Ophthalmology (SCO). The manuscript management system is completely online and includes a very quick and fair peer-review system, which is all easy to use. Visit http://www.dovepress.com/ testimonials.php to read real quotes from published authors. 